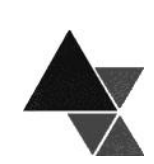

\title{
Produção e consumo local de alimentos: novas abordagens e perspectivas para as políticas públicas
}

\author{
Armando Fornazier ${ }^{1}$ e Walter Belik ${ }^{2}$
}

Nos últimos tempos cresceu a discussão sobre os sistemas agroalimentares locais, colocando em evidência diferentes conceitos que carregam em si considerações sobre a estrutura social, econômica e sobre os aspectos ambientais. Esse trabalho busca abordar conceitos de produção local de alimentos, principalmente no contexto internacional e o seu correspondente no Brasil com a recente introdução de políticas públicas atuando tanto na melhoria dos alimentos fornecidos aos consumidores, como nas estratégias de desenvolvimento rural para regiões mais necessitadas. Verificase que nas conhecidas abordagens de Foodsheds, Embeddedness, Foodmiles e "cadeias agroalimentares curtas" os objetivos do uso dos conceitos variam desde o aprofundamento das relações sociais e melhoria da qualidade do alimento, redução da emissão de gases que provocam o efeito estufa até propostas mais ambiciosas como alcançar o desenvolvimento econômico de determinadas regiões.

Palavras-chave: espaço, mercados agroalimentares locais, relações, segurança alimentar.

\section{Production and consumption of local food: new approaches and trends regarding the public policies}

Discussion about local agri-food systems have increased in these days, highlighting different concepts that are the basis for social, economic, and environmental structures. This study aims to report concepts of local food production, mainly, in the international context, and the matching concepts in Brazil, which has recently introduced public policies for improving the quality of food offered to consumers, as well as for rural development strategies in poor areas. It is observed in Foodsheds, Embeddedness, Food miles, and 'agri-food short chains' approaches that the goals of these concepts vary since the search for deeper social relationships, improvement of food quality, and reduction of greenhouse gas emission, until more ambitious proposals, so economic development in some regions can be reached.

Keywords: space, agri-food market, relationships, food security.

\footnotetext{
${ }^{1}$ Doutor em Desenvolvimento Econômico do Instituto de Economia. UNICAMP. Correspondência: Instituto de Economia. UNICAMP. Rua Pitágoras, no 353. Cidade Universitária. CEP. 13.083-857. Campinas, SP. E-mail: armandouenf@yahoo.com.br.

2 Professor Titular. Instituto de Economia. UNICAMP. E-mail: belik@eco.unicamp.br. 


\section{INTRODUÇÃO}

Desde os tempos coloniais o comércio internacional de alimentos tem um papel determinante na economia dos países e no padrão de consumo das populações. Para Adam Smith (1979) [1], a liberdade de comércio permitiria a aprofundar a divisão do trabalho e a especialização com vistas a ganhos de produtividade a custos cada vez menores em determinadas produções. Contudo, na agricultura, a natureza colocaria uma barreira à completa divisão do trabalho e, portanto os ganhos em termos de custos não seriam tão expressivos como na indústria. Dessa manira, raciocinando em termos relativos não seria compensador a um país se dedicar a agricultura quando pode "trocar todo o excedente do seu trabalho, de que não necessita, pelo excedente da produção dos outros homens" (Smith, 1978: 17) [1]. Tendo como base esses pressupostos a produção agrícola se expandiu nas regiões mais remotas visando satisfazer os mercados mundiais, sempre ávidos por alimentos baratos. Com isso, as presenças das grandes companhias produtoras e comercializadoras se disseminaram ao longo do século XX e as dificuldades técnicas ou logísticas passam a não representar impedimentos para a amplificação de um padrão mundial de produção e consumo de alimentos.

Mesmo em produtos não "commoditizados", por exemplo, as frutas, legumes e verduras (FLV), mecanismos de logística e processamento permitiram que esses produtos passassem a ser comercializados em mercados cada vez mais distantes. Nos mercados domésticos, com o avanço do comércio e a constituição de grandes cadeias varejistas tendo como base redes de suprimentos globais. Com isso, um dos critérios para a operação de compra de produtos da agricultura e da agroindústria passou a ser o custo o que levou a combinação de mercadorias produzidas em mercados locais com outras importadas de regiões distantes. Em resumo, fatores como a adaptação de cultivos em regiões mais propícias levaram a que determinados alimentos fossem produzidos com vantagens em certas regiões estabelecendo-se assim uma ligação entre mercados através de grandes distâncias.

Mais recentemente algumas mudanças estão sendo verificadas nesse sistema de produção e consumo de alimentos. Dois movimentos, contrários entre si, contribuem para a emergência de mudanças nesse modelo, a saber:

Pelo lado da produção e distribuição a introdução de inovações em informática e telecomunicações que permitiu ampliar a escala de operações de transformação do produto de base agropecuária. Com isso as matérias-primas utilizadas no processo de produção de alimentos puderam ser desconstruídas, montadas e remontadas ao redor do planeta segundo as necessidades colocadas pelas empresas e consumidores. Já no que se refere ao consumo, observa-se certo saturamento do mercado e uma busca por qualidade e especialidade, presente principalmente entre os consumidores de alta renda. Acrescente-se a isso uma preocupação maior com o meio-ambiente e com a contaminação dos próprios alimentos.

Evidentemente em um espaço global onde aproximadamente $1 / 6$ da humanidade ainda passa fome as novas tendências quanto à produção e o consumo de alimentos vão se espalhar com maior facilidade primeiramente nos países ricos e entre a população de alta renda. Entretanto já se observa alguma fratura no chamado "regime alimentar fordista" [2] com o avanço de sistemas locais de produção e com a crise financeira mundial que vem abalando o sistema de livre comércio.

Nos últimos anos cresceu o debate acerca da produção local de alimentos e seus objetivos na conexão entre produtores e consumidores. A produção local de alimentos tem sido debatida dentro de vários contextos, tanto na preocupação ambiental de sustentabilidade, em aspectos econômicos como geração de oportunidades para os produtores locais como alternativa à globalização, entre outras.

Com o crescimento da discussão de produção e consumo local de alimentos ou sistemas agroalimentares locais, também surgem em diversas partes do mundo conceitos e interpretações diferenciadas sobre as características dessa produção local e sua finalidade. Mais recentemente, essa temática se estendeu para o campo das políticas públicas com a introdução das compras governamentais (public procurement) de alimentos para escolas, creches, hospitais, entre outros equipamentos públicos, política essa associada ao desenvolvimento rural. Como se observa, os sistemas agroalimentares locais estão muito associados à questão do espaço (inserção da 
produção local, cadeias curtas) e meio ambiente (diminuição das emissões de gases, etc.), o que também gera controvérsias, pois a defesa da produção local pode também ser utilizada como mecanismo de proteção de determinados grupos, como por exemplo, dos agricultores locais.

A defesa em torno do desenvolvimento dos sistemas agroalimentares locais se apresenta de diversas maneiras no discurso político. Dependendo do contexto a preocupação pode ser mais social, econômica ou ambiental. Observa-se também diferenças na implementação dos programas e na avaliação de experiências utilizando conceitos que muitas vezes são sinônimos, mas têm suas especificidades.

Esse trabalho pretende abordar conceitos, experiências e objetivos da produção local de alimentos trazendo assim abordagens que fazem parte desse discurso, principalmente com base nas experiências internacionais, mas também fazendo uma ligação com o contexto brasileiro devido as crescentes iniciativas referentes à conexão entre produção e consumo, por exemplo, por parte de equipamentos públicos como escolas, creches, hospitais, entre outros. Para isso, adota-se a pesquisa bibliográfica em artigos e livros, bem como pesquisa documental em relatórios de projetos sobre produção local de alimentos.

As abordagens relatadas no texto são principalmente dos países de língua inglesa como os Estados Unidos e Reino Unido, bem como de outros países publicados em inglês. A preferência por esse enfoque se dá no sentido de introduzir novos autores que vêm trabalhando o tema dos circuitos locais ou cadeias curtas, além daqueles conhecidos e aplicados tradicionalmente nos estudos brasileiros. O esforço é o de trazer novas abordagens ainda pouco discutidas no Brasil, para que essas possam frutificar em estudos específicos da nossa realidade.

\section{O CONCEITO DE ALIMENTO LOCAL: DIFERENÇAS E SOBREPOSIÇÕES}

Dada à diversidade de conceitos que fazem parte da literatura de local food (produção local de alimentos ou sistemas agroalimentares locais), cabe escolher alguns que são mais utilizados, tanto no campo teórico, bem como implementados em projetos que podem ser públicos como uma política pública ou por atores sociais na busca de promover melhorias ambientais, econômicas e/ou sociais em um espaço. Assim, os conceitos a seguir fazem parte da discussão de local food que ocorre atualmente na Europa e Estados Unidos, porém, são muitas vezes transpostos para adoção de projetos ou análises das dinâmicas agroalimentares locais em outras partes do mundo.

O avanço da ciência com a divulgação eletrônica de artigos e livros tem facilitado aos pesquisadores conhecerem tópicos de estudo de diversas partes do mundo. Porém, muitos conceitos têm sido criados em situações bem delimitadas com o propósito de descrever um caso específico ou e até mesmo dentro de uma área específica da ciência. Esse é o caso do conceito de local food que pode ser entendido seja pelo lado econômico da diminuição de custos como pelo lado ambiental de gastar menos energia em transporte ou dentro do arcabouço da sociologia rural como o aprofundamento das relações entre produtores e consumidores, entre outros.

Porém, a prioridade a uma área de estudo pode dificultar a verificação de outros pontos relacionados a esse estudo que interferem na organização dos atores sociais ou na interpretação dos objetivos de determinadas ações.

\section{FOODSHEDS}

Os estudos de sistemas agroalimentares locais têm crescido dentro de uma perspectiva de uma maior valorização do espaço, considerando alguns fatores na produção como as distâncias entre produção e consumo, delimitando uma região em que ocorrem as etapas de produção e consumo. Um conceito adotado para isso é de "foodshed". Kloppenburg, Hendrickson e Stevenson (1996) [3] mencionam que o termo "foodshed" foi cunhado em 1929 (Hedden, 1929) ${ }^{1}$ e mais tarde surgem artigos sobre o tema como o denominado "Urban Foodsheds" de Arthur Getz (1991)2. O termo deriva em parte do conceito de "watershed" ou bacia hidrográfica. Assim, a substituição de "água" por "alimento" conecta o cultural "food" com o natural "shed". O termo "foodshed" torna-se uma metáfora, unificando e organizando os conceitos com o primado da unidade de lugar e pessoas, natureza e sociedade [3].

Os estudos de "foodshed" dessa forma buscam escolher uma região como em sua origem, por

\footnotetext{
${ }^{1}$ Hedden WP. How Great Cities Are Fed. Boston, MA: D. C. Heath and Company, 1929.

${ }^{2}$ Getz A. Urban foodsheds. The Permaculture Activist.24:26-27, 1991.
} 
exemplo, uma bacia hidrográfica e mostrar as conexões entre a produção e consumo. Peterset al. (2009) ${ }^{[4]}$ descrevem que vem crescendo o interesse em local food e um dos debates é a redução de distância que os alimentos percorrem. Porém, há discórdia entre a capacidade da agricultura local fornecer alimentos para essa população local. Dessa forma, se utiliza, por exemplo, mapas na metodologia para delimitar os potenciais foodsheds e áreas de terra que podem alimentar essa população. Inclusive os autores descrevem o modelo aplicado pelo estado de Nova Iorque, Estados Unidos. Os modelos buscam através de sistemas de informação geográfica estimar a capacidade de produção de alimentos em relação às necessidades alimentares dos centros populacionais daquele estado.

Mesmo o foodshed tendo uma relação maior com a geografia do espaço, Feenstra (1997) [5] descreve que o local foodshed não descreve somente a área geográfica e os alimentos que podem crescer seu cultivo, mas também, elementos culturais e sociais da comunidade. Sendo que, investigar esses elementos é essencial para entender aspectos únicos do sistema alimentar na comunidade. Nos Estados Unidos muitos estudos e projetos de produção local de alimentos buscam analisar a sustentabilidade dos alimentos e sistemas agrícolas e a viabilidade (feasibility) de criar maiores economias alimentares locais [5]. O'Sullivan (2012) [G]avalia vários trabalhos sobre produção local de alimentos e descreve que em geral, há uma tendência para a análise de foodshed, mas simplificam a análise de viabilidade do local ajustando oferta e demanda dentro de uma área, sem considerar ligações comerciais e transporte. A Figura 1 mostra a viabilidade de um sistema local de alimentos onde fica característico esse desalinhamento.

Figura 1. Viabilidade dos alimentos locais

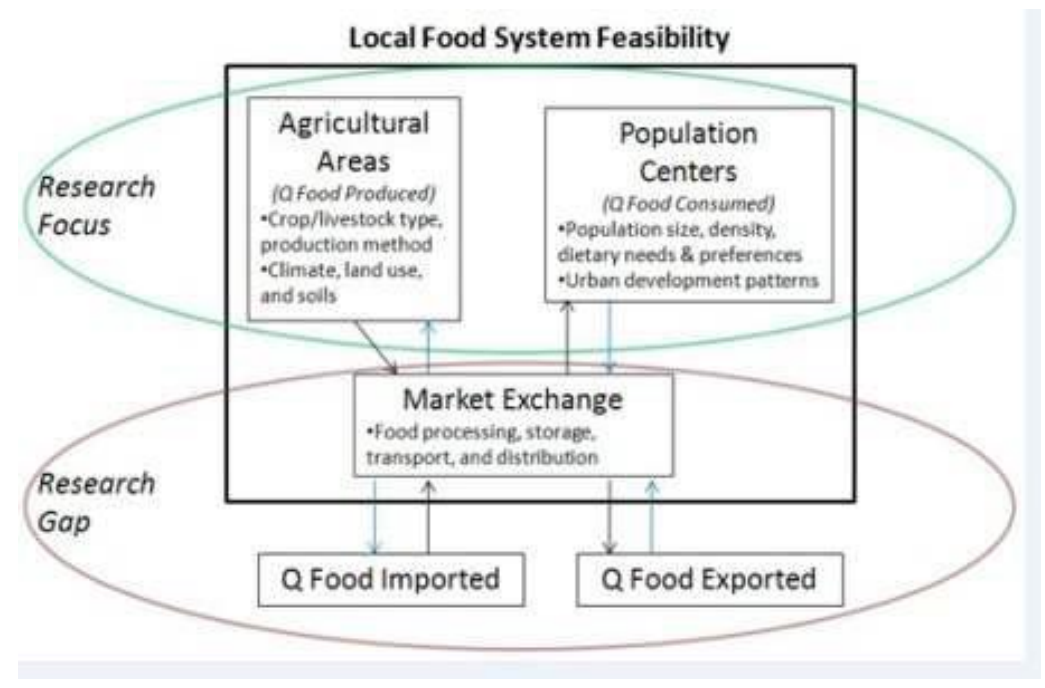

Fonte: O’Sullivan (2012) [6].

O conceito de foodshed reconstrói a geografia dos sistemas alimentares por forçar que decisões sociais e políticas sejam orientadas dentro de espaços específicos [7]. Porém, em determinado espaço, podese dar prioridade a questões econômicas como a viabilidade e nesse aspecto incluir não apenas oferta e demanda, mas, escalas, transações, etc., bem como a questões ambientais de diminuir gastos de energia em transporte, por exemplo, ou no aspecto social e político das relações, tanto no nível dos produtores, como entre produtores e consumidores, bem como as relações com outras organizações e instituições dentro e fora do foodshed como o Estado, as corporações, mercados externos, entre outras. O conhecimento de impactos ambientais é bem desenvolvido nos estudos de foodshed em comparação com os elementos econômicos e sociais [6]. 
Embora, esses elementos sociais e econômicos não estejam presentes ou mais aprofundados em muitos estudos de foodshed, a defesa dessa produção local consta de elementos econômicos, sociais e ambientais, o tripé da sustentabilidade.

Nos Estados Unidos, o Departamento de Agricultura (USDA), através da Agência de Gestão de Risco (USD A Risk Management Agency) e o Farm Credit
Council têm incentivado que produtores criem negócios locais baseado no foodshed com o objetivo de fortalecer os sistemas de alimentos locais e regionais. Como parceiros desse projeto há associações de produtores orgânicos e agricultura sustentável. A Figura 2 mostra os objetivos do programa New American Foodshed incentivado pelo USDA.

Figura 2. Concepções do Foodshed nos Estados Unidos

\section{The New American Foodshed}

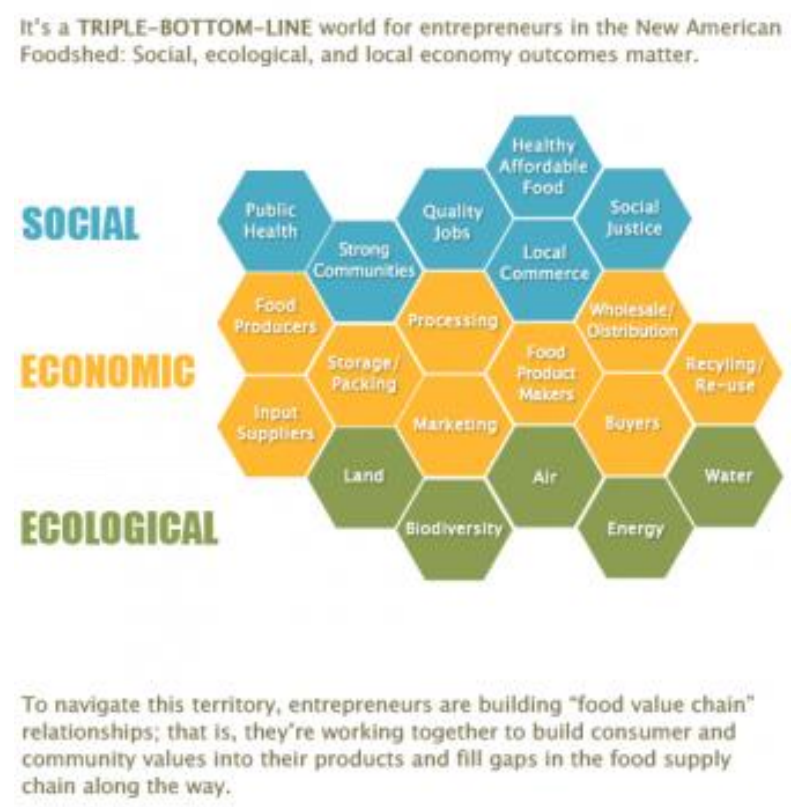

Fonte: Foodshed (2013) [8].

Fatores como a escala de produção e o pouco acesso a determinadas infraestruturas, por exemplo, para o transporte e algumas etapas de processamento como limpeza e embalagem podem criar dificuldades para os produtores, reduzindo a sua participação na produção ou introduzindo a comercialização com agentes intermediários, o que impactaria na sua rentabilidade. Para isso, projetos de incentivo a produção local também necessitam inserir outras questões como logística, preferências dos consumidores, entre outros. Morley, Morgan e Morgan (2008) [9] descrevem a importância dos Centros de Alimentos ou Food Hubs na produção local.
De acordo com os autores [9], citando o exemplo do País de Gales, Reino Unido, necessita-se de um mecanismo em que os pequenos produtores podem acessar coletivamente facilidades intermediárias que permite negociar com grandes clientes como supermercados, fornecedores de serviços ou consórcios de contratos públicos. Os Food Hubs têm relevância nesse contexto. Assim, o conceito de Food Hubs assume que no mercado há muitos atores envolvidos e que a função de coordenação poderá aumentar a eficiência das relações de mercado. Nos Estados Unidos, o USDA tem incentivado nos projetos de Foodshed os Food Hubs para fornecer aos 
produtores acesso aos mercados maiores, muitas vezes mais lucrativos e estáveis [8].

Mesmo considerando que a produção local tem objetivos mais voltados ao meio ambiente ou ao social, necessita-se levar em consideração a adoção de ações para a promoção de mudanças produtivas, o que requer estudos de organização dos atores sociais, mercados, etc. Feagan (2007) [7] descreve que precisamos entender que o local e a comunidade (regiões para o assunto) não são ilhas para si, mas interdependentes e dinâmicos na sua constituição. Assim, os trabalhos de produção local de alimentos devem ter em conta uma relação com os conceitos vinculados de foodshed, que inclui tipos de produtos cultivados, como é cultivado, por quem, de acordo com os tipos de necessidades culturais, sociais e econômicas ligadas, maneiras complexas e um tanto imperceptíveis, bem como fatores socioculturais nos níveis macroeconômicos e políticos. Como relatam Du Puis e Goodman (2005) [10], no discurso dos ativistas alimentares dos Estados Unidos, cresce a discussão de foodsheds e foodmiles onde há conexões cada vez mais fortes entre a localização dos sistemas alimentares e a promoção da sustentabilidade ambiental e justiça social.

\section{FOOD MILES}

Outra discussão na produção local de alimentos é o conceito de foodmiles ou milhas (distância) percorridas pelos alimentos. Os estudos sobre foodmiles têm crescido com a discussão da necessidade de redução dos gases de efeito estufa (GEE) para o planeta e a preocupação com a sustentabilidade. O conceito de foodmiles é baseado na noção simplista de que quanto mais o alimento viaja entre a fazenda e o prato, maior deve ser o seu impacto ambiental em termos negativos. $\mathrm{O}$ termo foi aparentemente cunhado no Reino Unido no início de 1990 e foi por diversas vezes atribuído ao Relatório "The Food Miles Report" publicado em 1994 pela SAFE Alliance e com o Dr. Tim Lang [11].

O termo foodmiles passa assim ser usado para demonstrar que um alimento é mais ou menos sustentável. Iles (2005) [12] descreve que cada vez mais, fornecedores locais de alimentos, grupos de produtores e governantes locais estão fazendo de várias maneiras representações interativas e buscando provar não somente que milhas elevadas são prejudiciais, mas que os alimentos locais são superiores. Através do foodmiles, ativistas chamam para uma re-localização das cadeias produtivas de alimentos para criar um sistema de produção alternativo para atender as necessidades dos produtores. Kemp et al. (2010) [11] descreve que redes varejistas de alimentos do Reino Unido têm endossado o movimento compre local (buy local) através de promessas e compromissos para produtos de origem local. Iles (2005) [12] descreve que nos Estados Unidos na sua campanha de compra local de alimentos (Buy Local Food) o Conselho Ambiental de Oregon utilizou-se do seguinte apelo: "ao apoiar os produtores locais e fazendeiros, você apoia sua economia local" (Oregon Environmental Council, 2003) ${ }^{3}$. Assim, além de preocupação ambiental, verifica-se nesse caso uma preocupação com a economia local e oferta de oportunidades para o aumento do emprego e elevação da renda.

$\mathrm{Na}$ União Europeia (UE), o Comitê das Regiões também destaca a importância dos "sistemas alimentares locais" nos aspectos econômico, social e ambiental. Dentre os benefícios econômicos o documento [13] descreve: programas de qualidade; geração de empregos na agricultura e na produção alimentar, incluindo a transformação, a distribuição, a comercialização e os serviços e atividades associadas à venda, principalmente nas zonas rurais remotas, nas periferias urbanas, nas regiões vulneráveis e nas zonas mais desfavorecidas; efeito multiplicador local, entre outros. Os benefícios sociais descritos vão desde a maior confiança e possibilidade de rastreabilidade imediata dos produtos, assim como a coesão social e espírito de comunidade. Dos benefícios ambientais o documento descreve:

\begin{abstract}
Os sistemas alimentares locais têm benefícios ambientais graças a métodos de produção mais sustentáveis, a externalidades de transporte (a chamada "quilometragem dos alimentos") mais reduzidas e à possibilidade de criar sistemas circulares com base nos resíduos orgânicos e nas energias renováveis; cada alimento percorre uma determinada distância (quilometragem dos alimentos) devido ao transporte entre a zona de produção local e o consumidor, que provoca emissões de carbono. Isto se aplica tanto aos alimentos frescos como aos (ingredientes dos) alimentos transformados. Os sistemas alimentares locais contribuem para reduzir a pegada ambiental de uma comunidade (União Europeia, 2011, p. C 104/3) [13].
\end{abstract}

\footnotetext{
${ }^{3}$ Oregon Environmental Council. Buy Oregon Campaign, 2003. Disponível em: www.orcouncil.org/Partnerships/Agriculture/Pledge.htm.
} 
Além da importância do foodmiles ou milhagem dos alimentos, o documento destaca que um produto alimentar local deve ter de preferência uma pegada de carbono (carbon foot print) inferior à de um produto importado semelhante. Assim como, os mercados locais para produtos alimentícios contribuem para a manutenção da biodiversidade e podem facilitar a gestão de resíduos e energias renováveis.

Porém, mesmo a discussão de foodmiles tendo uma maior ênfase na sustentabilidade, não é consenso que a produção local é mais sustentável que a produção global em algumas análises como a emissão de GEE, isso dadas as questões como a logística e eficiência produtiva que podem ser melhores em cadeias globais. Coley, Howard e Winter (2009) [14] analisam dentro da concepção de foodmiles uma aplicação empírica contrastando dois sistemas de distribuição com base na emissão de carbono. $\mathrm{O}$ resultado do estudo é que se um cliente leva uma distância de ida e volta com mais de $6,7 \mathrm{~km}$ para comprar vegetais orgânicos, por exemplo, em uma fazenda, suas emissões de carbono tendem a serem maiores do que as emissões do sistema de emissões de armazenamento a frio, embalagem, transporte para um centro regional e transporte final a porta do cliente utilizado por grandes fornecedores de alimentos. Assim, os autores sugerem que algumas ideias por trás do localismo na produção de alimentos devem ser revistas. A Figura 3 mostra as fontes de recursos fósseis e emissões de carbono no sistema de grande escala e a Figura 4 é referente a pequena escala.

Figura 3. Emissões de carbono no sistema de grande escala no Reino Unido

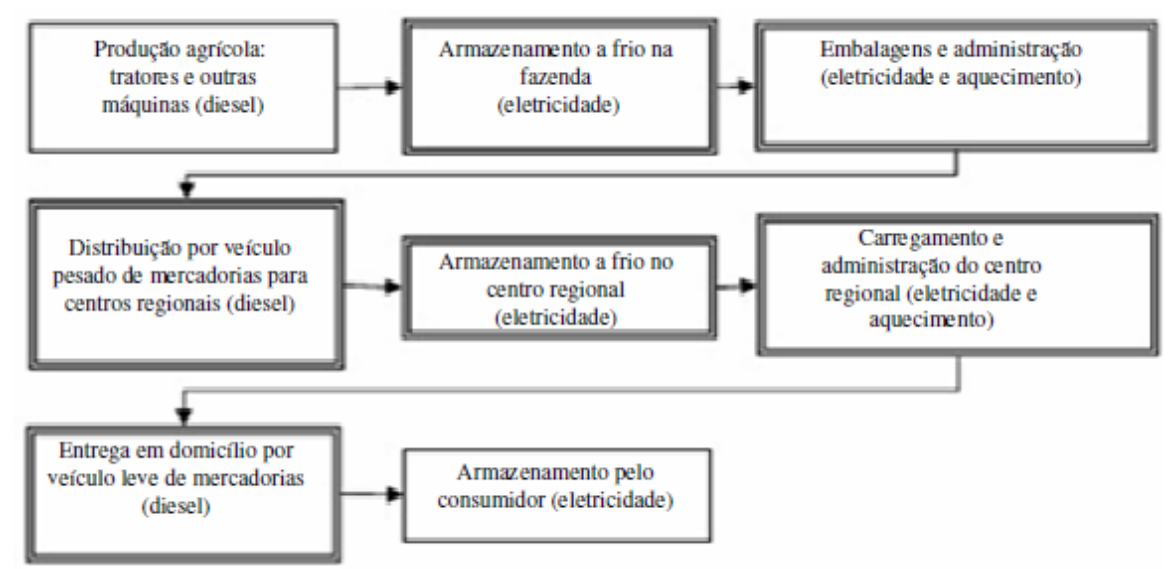

Fonte: Coley, Howard e Winter (2009) [14].

Figura 4. Emissões de carbono no sistema de pequena escala no Reino Unido

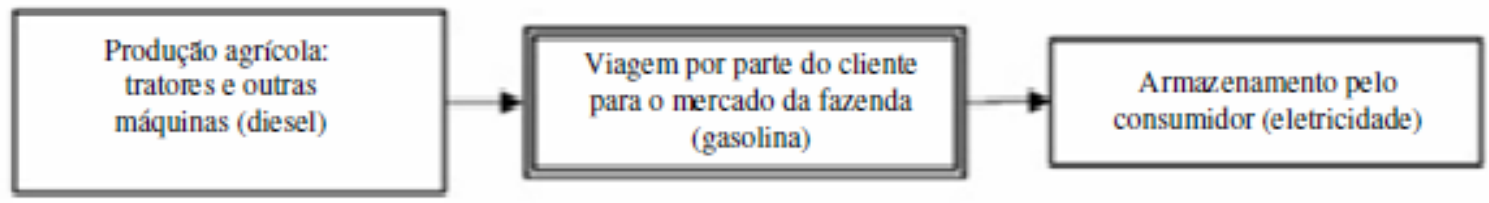

Fonte: Coley, Howard e Winter (2009) [14]. 
A análise dos autores das Figuras 3 e 4 focam mais na questão ambiental, porém, quando se trata de questões como sustentabilidade, por exemplo, é comum verificar aspectos econômicos e sociais também. Assim, a maior eficiência energética ou emissão de $\mathrm{CO}_{2}$ analisada isoladamente pode ser uma boa opção para pensar questões como aquecimento global, mas, não toca nem mesmo nas questões ambientais locais como, por exemplo, a possibilidade de uma agricultura menos intensiva em produtos químicos e a melhor proteção dos solos e mananciais hídricos das regiões produtoras de alimentos locais. Apesar desses problemas o conceito de foodmiles segue sendo utilizado apenas na sua dimensão ambiental. Como ilustração, o USDA (2010) ${ }^{[15]}$ na descrição dos conceitos de produção local de alimentos e sua importância dá um enfoque maior nas emissões de $\mathrm{CO}_{2}$ e distância percorrida (foodmiles), ou seja, a distância que os produtos alimentares viajam do local de produção para a localização onde é vendido ao consumidor final.

Mesmo em questões ambientais há divergências quanto a comparação de global e local na redução de efeitos ambientais. Nos estudos de foodmiles ou produção local de alimentos as comparações ao extremo entre local e global podem não ser muito realistas. Coley, Howard e Winter (2009) ${ }^{[14]}$ descrevem que o trabalho de Sonnino e Marsden (2006) [16] tem argumentado que é um erro olhar redes de alimentos "alternativas" e "convencionais" em esferas separadas. Em vez disso, há uma série de concorrentes agroalimentares geográficos construídos sobre diferentes conjuntos de qualidade, convenções comerciais e diferentes graus de embeddedness horizontal e vertical. Assim, Coley, Howard e Winter (2009) [14] descrevem que o consumidor de alimento não é confrontado simplesmente com a escolha simplista entre "local-bom" e "global-mal". Emissão de carbono não é a única forma de avaliar decisões de compra, há outras questões como implicações para a biodiversidade e paisagem, emprego local, comércio justo e justiça social internacional. Assim, é necessário um debate público sobre sistemas alimentares em que frases de efeito como "foodmiles" que foram úteis no início para chamar a atenção da mídia, agora possam dar lugar a abordagens mais aprofundadas baseadas em casos de estudos estratégicos de sistemas varejistas específicos ou setores de commodities chave.

\section{EMBEDDEDNESS}

O termo embeddedness referido anteriormente por Sonnino e Marsden (2006) [16] faz parte de estudos de sistemas agroalimentares locais. Hinrichs (2000) [17] descreve que o termo tem raízes no trabalho de Karl Polanyi $(1957)^{1}$ no qual se constata que a economia humana é enraizada (embedded) e emaranhada (enmeshed) em instituições, econômicas e não econômicas. Assim, para muitos a noção de social embeddedness tornou-se uma prática abreviada para laços sociais assumidos para modificar e aumentar interações econômicas humanas.

Muitos estudos relacionados a mercados de alimentos passaram a adotar o conceito de embeddedness com o objetivo de destacar outras características nas relações de mercado e não apenas os mecanismos tradicionais de oferta e demanda. O conceito de embeddedness pode ser um dispositivo teórico muito útil para aprofundar a investigação entre alimento e território [16]. Porém, quanto ao espaço, Du Puis e Goodman (2005) [10] chamam a atenção para a questão de que por uma parte do discurso, o localismo é uma forma de proteção de determinados lugares contra outros lugares, atuando como uma forma de resistência à concepção abstrata de "global". Sendo que em alguns casos, o regionalismo pode andar sobre o fio da navalha entre o esforço de desenvolvimento regional e uma forma de xenofobia. Sonnino e Marsden (2006) [16] descrevem que de modo geral, a noção de embeddedness tem sido amplamente utilizada para enfatizar o componente social da ação econômica. Nos estudos agroalimentares, o embeddedness tem provado ser um conceito eficaz para enfatizar mais o caráter social entrincheirado das redes alternativas de alimentos. Contudo, vários estudiosos têm alertado contra as limitações dos estudos que utilizam a noção de embeddedness exclusivamente para descrever e enfatizar a dimensão social das redes alternativas de alimentos ${ }^{[16]}$.

O conceito de embeddedness tem sido assim utilizado para demonstrar as relações entre produtores e consumidores, por exemplo. Feagan (2007) [7] observa que a noção de embeddedness tem aumentado na

\footnotetext{
+ Polanyi K. The economy as instituted process. In: Polanyi K.; Arensberg CM, Pearson HW. Trade and Markets in the Early Empires. Free Press, Glencoe, IL, p. 243-270, 1957.
} 
literatura de sistemas agroalimentares locais. $\mathrm{O}$ conceito é descrito nos processos socioculturais associados com relações entre produtores e consumidores e as novas ligações que daria no âmbito da produção de alimentos seriam uma forma de reembedded entre a comunidade e os sistemas locais. Hinrichs (2000) [17] lembra que embeddedness no sentido de conexão social, reciprocidade e confiança é muitas vezes visto como uma marca (e vantagem comparativa) em venda direta de produtos agrícolas.

O conceito de embeddedness, como foi visto anteriormente, tem uma forte conexão com o social, a criação de laços, por exemplo, de confiança. O embeddedness não é apenas a dependência do social sobre o econômico, mas, baseia-se na incorporação e manipulação do espaço, envolvendo economia social e natureza. $\mathrm{O}$ conceito como alguns pesquisadores começam a discutir no contexto dos alimentos abarca também as dimensões econômicas, ambiental, cultural e política das redes de alimentos ${ }^{[16] .}$

Dessa forma, muitos estudos locais fazem abordagens de qualidade, confiança, redes, entre outros. Du Puis e Goodman (2005) [10] fazem os seguintes questionamentos: Quem vai definir o local? O que é exatamente qualidade e em quem você confia para lhe fornecer essa qualidade? Que tipo de sociedade está no embedded local? Com que você se importa e como? Assim, os autores relatam que assim como foi destacado por como Hinrichs, Winter, o local como conceito intrínseco implica na inclusão e a exclusão de pessoas, pedaços de um território e modos de vida. A representação do local e de suas construções - qualidade, embeddedness, confiança e cuidados (care) - privilegia certas categorias analíticas e trajetórias, cujo efeito é naturalizar e obstruir as políticas do local.

Além das relações sociais nas transações, o embeddedness faz parte de estudos locais que tratam das relações sociais para outros objetivos além da produção como as relações dos indivíduos com a natureza. Murdoch, Marsden e Banks (2000) [18] focam o embeddedness das relações econômicas com as relações naturais. Os autores argumentam que as relações econômicas estão em processos contínuos sujeitos ao desenraizamento (disembedding) e re-enraizamento (reembedding), associada com esforços para outflanknature (apropriação e substituição, por exemplo) e esforços para resistir a essas manobras outflanking (levar vantagem) pelo restabelecimento biológico, como oposição ao industrial, processos com cadeias de alimentos. Com isso, os sistemas de produção agroalimentares de qualidade estão sendo enraizados em ecologias locais. Os autores [18] destacam que processos como localness, naturalness e embeddedness como suficientes nas questões de qualidade, mas, como as qualidades são afirmadas e negociadas em cadeias de alimentos.

A discussão sobre o sistema agroalimentar local apresenta diferenças entre a visão norteamericana e a europeia. Du Puis e Goodman (2005) [10] descrevem que nos Estados Unidos muito da literatura acadêmica sobre esse tema ecoa em ativistas sobre sistemas alimentares alternativos construído sobre normas sociais alternativas. Já na Europa a localização tornou-se parte integrante de novo sistema de governança de desenvolvimento rural para melhorar os meios de vida rural e preservar o patrimônio europeu. Assim, na Europa, o incentivo a sistemas agroalimentares locais surgiu no contexto de novas formas de governança rural descentralizada em paralelo com o lento processo de reforma da Política Comum da União Europeia (PAC). Mas, em ambos os casos, apesar de diferentes razões, o local tornou-se "belo" como era "pequeno" (pluriativo, na Europa) em 1970 e 1980, "orgânico" ("multifuncional”) em 1990 ou nos Estados Unidos "wilderness" no início do século [10].

$\mathrm{Na}$ literatura europeia também há uma ênfase na importância da produção local para o desenvolvimento rural das regiões menos desenvolvidas [11]. Du Puis e Goodman (2005) [10] citam os estudos em que o local naturalizado (naturalized local) é anunciado como novas formas econômicas que configuram o surgimento do "novo paradigma de desenvolvimento rural" para alguns observadores (Ploeg et al., 2000) [19]. O local com o enfoque em embeddedness é estudado em relações de cadeia como na de produção orgânica [18]. Feagan (2007) [7] descreve que nos estudos europeus há uma ênfase também em cadeias agroalimentares curtas ou shortened food chains (SFCs) citando Renting, Marsden e Banks (2003) [20].

\section{CADEIAS AGROALIMENTARES CURTAS E ALTERNATIVAS}

As cadeias agroalimentares curtas ou shortened food chains (SFCs) e redes alternativas de alimentos ou alternative food networks (AFNs) são termos que fazem parte das referências europeias sobre produção local de alimento, principalmente analisando questões de 
qualidade, não qualidade apenas nas características físicas dos alimentos, mas também outros atributos intangíveis como questões sociais e ambientais. Renting, Marsden e Banks (2003) [20] relatam que no estudo do projeto IMPACT (projeto financiado no âmbito da Comissão Europeia) há três alternativas ou cadeias curtas de fornecimento de alimentos - short food supply chains (SFSCs): agricultura orgânica, produção de qualidade e venda direta. Os autores relatam que o conceito de SFSC é mais específico que AFNS, pois abrange inter-relações entre atores que estão envolvidos na produção, processamento, distribuição e consumo de novos produtos alimentícios.

A lógica das cadeias agroalimentares curtas está na aproximação de produtores e consumidores. Feagan (2007) [7] descreve que como nos trabalhos sobre mercados agrícolas, hortas comunitárias, terroir e cadeias agroalimentares curtas, a ideia é de um maior enraizamento (embedded) no conjunto de relações entre produtores e consumidores, bem como o local e a proveniência de alimentos cultivados. Du Puis e Goodman (2005) ${ }^{[10]}$ relatam que com a capacidade para ressocializar ou re-espacializar os alimentos, as SFSC estão em uma posição para valorizar as qualidades do local e seus atributos sócio ecológicos terroir, conhecimento tradicional, espécies crioulas, por exemplo, que pode ser traduzida em maiores preços. Assim, o local torna-se uma fonte de valor. O local e as SFSC são dentro dessa perspectiva empiricamente e teoricamente unidos principalmente na forma de renda econômica, embora sem atenção explícita para a política de apropriação ${ }^{[10]}$.

Os sistemas agroalimentares locais em alguns casos são tratados como oposição a commoditização dos alimentos, principalmente nos processos industriais onde o produto perde características como onde foi produzido, quem produziu etc. Feagan (2007) [7] descreve que posições críticas e práticas avançadas da literatura de Sistemas Agroalimentares Locais em torno da necessidade de reconstruir o local em face da industrialização e sistemas agrícolas globalizados são em paralelo, embora teoricamente aprofundado, uma discussão exclusiva de geógrafos. Renting, Marsden e Banks (2003) [20] descrevem que com as cadeias curtas de fornecimento de alimentos (SFSC) as relações entre produtores e consumidores são encurtadas, redefinindo novos sinais claros entre procedência, atributos de qualidade dos alimentos e construção de cadeias transparentes em que os produtos cheguem ao consumidor com um valor agregado de informações. É importante assim o papel do transportador no encurtamento das reações entre produção de alimentos e localidade, buscando melhorar o reenraizamento da agricultura e tornando-a uma atividade mais ambientalmente sustentável. As cadeias curtas dessa forma buscam aproximar o produtor e o consumidor, mas, há também uma crítica aos processos industriais tradicionais de alimentos. Renting, Marsden e Banks (2003) [20] relatam que desde 1970 alguns fatores como os escândalos com salmonella, mal da vaca louca ou Bovine Spongiform Encephalopathy (BSE) e resíduos de dioxinas no leite alteraram a percepção dos consumidores com uma desconfiança crescente na qualidade dos alimentos da indústria tradicional. De modo geral, as cadeias agroalimentares curtas são defendidas como alternativa a globalização, principalmente contra o poder de grandes corporações. Du Puis e Goodman (2005) [10] descrevem que no nível meso, os episódios de "crises" alimentares (foodscares) e aumento de preocupações dos consumidores com a saúde e alimento seguro na Europa estimularam uma "virada" para a qualidade no fornecimento de alimentos e reforço no apoio a agricultura multifuncional. Os autores [10] descrevem que defensores dos sistemas agroalimentares locais na Europa, enquanto indiscutivelmente menos propensos ao idealismo radical de transformação dos movimentos sociais dos Estados Unidos, consideram a re-localização e re-enraizamento (re-embedding) como estratégias para realizar um rural imaginário eurocêntrico e defender a identidade cultural contra o domínio dos Estados Unidos, a globalização corporativa.

A produção local e cadeias agroalimentares curtas é também introduzida através do Movimento Slow Food. Miele e Murdoch (2002) [21] descrevem que o Slow Food surgiu da cultura de alimentos que cercava as cozinhas regionais na Itália, sendo estabelecido em 1986. A motivação inicial era a crescente preocupação com o impacto potencial do americanizado fast food (McDonald's ${ }^{\circledR}$ ) nas culturas alimentares locais. A preocupação inicial era que a chegada do McDonald's ${ }^{\circledR}$ ameaçava os restaurantes que serviam pratos locais que, por sua vez, teriam uma estreita ligação com os sistemas locais de produção de alimentos. Assim, para o movimento Slow Food, a proteção dos hábitos de alimentação tradicionais requer a promoção geral das culturas alimentares locais. Du Puis e Goodman (2005) [10] citam, por exemplo, o trabalho de Miele e Murdoch (2002) [21] relatando que um imaginário rural também infunde a caracterização de AFNs e SFSC contra os efeitos homogeneizadores dos sem lugares (placeless), 
globalizado, modos industriais de provisão de alimentos e a "Macdonaldização" das culturas alimentares regionais.

Nas abordagens como no Foodsheds, Embeddedness, Foodmiles e cadeias agroalimentares curtas percebe-se que o local é algumas vezes abordado mais como espaço de relações sociais ou a preocupação maior pode ser da produção local como mecanismo de diminuir efeitos globais como a emissão de gases de efeito estufa, bem como um espaço para atuação via desenvolvimento econômico através da organização dos atores sociais em uma atividade. Assim, além dos objetivos descritos anteriormente, a produção local passa a fazer parte de políticas públicas, seja de desenvolvimento rural, por exemplo, para dinamizar as regiões de baixa dinâmica econômica, bem como nas políticas públicas de compras governamentais para equipamentos públicos como escolas, creches hospitais, presídios, entre outros.

\section{OS FUNDAMENTOS PARA A ADOÇÃO DO PARADIGMA DA PRODUÇÃO LOCAL DE ALIMENTOS}

Nos projetos de desenvolvimento rural na Europa, principalmente com o enfoque de desenvolvimento local ou regional há um debate sobre a importância da promoção dos sistemas agroalimentares locais, por exemplo, em Renting, Marsden e Banks (2003) [20], Ploeg et al. (2000) [19]. Nesses estudos como descrito anteriormente passa a se valorizar mais características de qualidade dos alimentos como o maior acesso a informações de quem produziu, questões ambientais como a conservação do espaço, multifuncionalidade da agricultura, entre outros. A União Europeia (2011) [13] descreve que o desenvolvimento de sistemas alimentares locais é importante para os órgãos de poder local e regional, aos quais cabe um papel determinante na programação, na promoção e no apoio ao desenvolvimento sustentável da economia rural, incluindo a criação de condições favoráveis aos sistemas alimentares locais. Esse estudo relata que para tirar o máximo proveito de um modelo plural, há a necessidade de reforçar as ligações entre a agricultura e as expectativas do consumidor, assim como entre a produção nas explorações agrícolas e os mercados locais, regionais e internacionais.

A preocupação em encurtar distâncias entre produtores e consumidores, seja, por questões sociais de embeddedness ou por questões ambientais como o foodmiles tem trazido uma discussão que, não é apenas da produção rural, mas, a importância de também inserir na produção de alimentos espaços nas áreas urbanas. Feenstra (1997) [5] descreve estudos que recomendam o estabelecimento de conselhos de política alimentar para coordenar os diferentes elementos dos sistemas alimentares urbanos e desenvolvimento de ligações entre consumidores e produtores locais. Das possibilidades de produção, seja as hortas comunitárias ou a produção individual pode ser uma fonte significante de alimentos locais para os residentes urbanos e rurais. A União Europeia (2011) [13] relata que a política agrícola comum após 2013 além de reorientar as suas ajudas para a promoção do emprego e a manutenção da presença agrícola em todas as zonas cultiváveis da Europa, deve dar especial atenção às zonas vulneráveis, onde inclui também as situadas nas periferias urbanas.

A conexão do rural com o urbano na produção de alimentos faz parte do debate de sistemas agroalimentares locais, tanto como experiências privadas entre os atores sociais, bem como nas políticas públicas. Hinrichs e Kremer (2002) [22] destacam que nos Estados Unidos o desenvolvimento de sistemas locais de alimentos têm enfatizado a criação de novos arranjos de mercado para ligar mais diretamente produtores e consumidores. Um dos exemplos descritos no trabalho é sobre o mercado varejista dos produtores e Community Supported Agriculture (CSA). O CSA é baseado em um pacto entre os agricultores e os consumidores locais dos alimentos produzidos. As pessoas se juntam ao CSA normalmente comprando uma parte (usualmente entre US\$200-400) no início da época de cultivo tornandose assim membros e consumidores da produção. Por apoiar a produção no fornecimento de incentivos financeiros antes da temporada de produção, os consumidores normalmente recebem uma oferta semanal de produtos frescos, possivelmente frutos e vegetais produzidos em outras propriedades quando disponível. O tipo e a quantidade de alimentos variam de acordo com as estações do ano e normalmente os membros reconhecem esse arranjo, sendo que riscos como os de colheita e mau tempo têm sido historicamente suportados. Outros projetos nos Estados Unidos incluem os incentivos a hortas comunitárias, transporte público dos alimentos para varejistas convencionais e vales alimentos saudáveis para serem usados nos mercados locais dos produtores [22]. 
As ações para incentivar a produção local de alimentos podem ocorrer por preocupação dos consumidores, assim como por meio de projetos sociais de pessoas ou organizações na busca de ajudar outros atores sociais, bem como algumas ações podem se transformar em política pública. A produção agroalimentar local pode também atuar tanto no desenvolvimento de agricultores mais necessitados, oferecendo uma oportunidade de mercado, assim como oferecer alimentos aos consumidores mais necessitados. Dentro dessa lógica, muitos estudos têm destacado a importância da produção local de alimentos para os mercados institucionais ou compras governamentais.

Nos Estados Unidos o programa Farm-toSchool foi criado em muitos estados com o objetivo de aproximar os consumidores, principalmente crianças e os produtores locais. Morgan e Sonnino (2008) [23] relatam que assegurar alimentos locais de fornecedores locais é uma das marcas do movimento Farm-to-School nos Estados Unidos e mais de 1.000 programas em 38 estados estão comprando produtos frescos de fazendas locais. Os autores [23] relatam que esse movimento tem o potencial de ser um dos mais importantes movimentos sociais do país e combustível de crescimento de cadeias alimentares mais sustentáveis além de ajuda às comunidades por meio de suas escolas, reconectando os produtores de alimentos.

A produção local pode ser vista mais do lado do produtor com a importância para o aumento de renda rural e diminuição da pobreza, por exemplo. No caso dos Estados Unidos, Izumi, Wright e Hamm (2010) [24] destacam que os agricultores que vendem para um Programa de Merenda Escolar (farm to school programs) enfatizam a importância da diversificação de suas estratégias de mercado, pois, com uma parte da produção indo para a merenda escolar e outra parte indo para outros mercados privados, os produtores dividem os riscos. Os autores destacam também pelo lado dos consumidores (escolas), esses programas introduzem hábitos alimentares mais saudáveis para as crianças atendidas. A introdução de alimentos mais saudáveis é uma preocupação principalmente com o aumento da obesidade infantil.

Nos Estados Unidos, a iniciativa de compras para a alimentação escolar surgiu da organização social. O programa Farm-to-School é adotado em muitas localidades. Feenstra e Ohmart (2012) [25] descrevem que o movimento Farm-to-School surgiu em meio à crescente preocupação pública sobre saúde na infância e obesidade, bem como pelo aumento da conscientização sobre os desafios ambientais e econômicos do sistema agroalimentar agrícola nos Estados Unidos. No início, boa parte dos recursos era doada pela W.K. Kellogg Foundation, USDA e fundações locais, por exemplo, na Califórnia. Com o tempo, os estados passaram a incentivar e o programa evoluiu para uma escala nacional. O programa representa muito mais que a prevenção contra a obesidade infantil, benefícios para a saúde pública e criação de mercados para os agricultores familiares. Pode-se afirmar que se o Farm-to-School sobreviver e crescer será uma grande contribuição para a preservação das terras agrícolas, sustentabilidade ambiental e particularmente o fornecimento de empregos e impulsionamento das economias locais [25].

Já na Europa, Sonnino (2009) [26] descreve que a implementação de uma política de aquisições de alimentos para a merenda escolar em capitais como Roma, onde se buscou fazer uma revolução da qualidade, convidando representantes de organismos de certificação orgânica para identificar os produtos, bem como nutricionistas com o objetivo de indicar quais produtos orgânicos são mais saudáveis para as crianças. Assim, as relações da produção com os consumidores passaram a controlar certas características de qualidade no mercado de alimentos. Morgan e Sonnino (2008) [23] também destacam como a compra governamental (public procurement) para a alimentação alterou a produção para uma agricultura mais sustentável em diversos países. Esse tipo de aquisição pode mudar a produção para uma agricultura mais local, promovendo uma re-localização da produção, reduzindo foodmiles, no caso, gastos de energia para o transporte ${ }^{[27]}$.

No Brasil, ações de compras governamentais da agricultura familiar são defendidas principalmente dentro da perspectiva de melhoria da alimentação, por exemplo, em escolas, assim como fornecer alimentos a quem tem dificuldades de acesso (insegurança alimentar) e geração de renda para produtores locais. Graziano da Silva, Belik e Takagi (2006) ${ }^{[28]}$ quando descrevem da atuação dos programas de combate à fome (segurança alimentar) relatam que esses devem "amarrar" a ponta do consumidor pobre, que possui renda insuficiente para comprar alimentos necessários à outra ponta onde está a produção, onde nessa ponta, o agricultor familiar está indo à falência porque não possui quem compre a sua produção. 
Como política de compras governamentais da agricultura familiar ou pequenos produtores, no Brasil criou-se o Programa de Aquisição de Alimentos (PAA) em 2003 com a finalidade de incentivar a agricultura familiar através de ações vinculadas à distribuição de produtos agropecuários para as pessoas em situação de insegurança alimentar e a formação de estoques estratégicos [29]. Em 2009 alterou-se o Programa Nacional de Alimentação Escolar (PNAE) exigindo que pelo menos $30 \%$ (trinta por cento) dos recursos financeiros repassados pelo Fundo Nacional de Desenvolvimento da Educação (FNDE) deverão ser utilizados na aquisição de gêneros alimentícios diretamente da agricultura familiar e do empregador rural familiar ou de suas organizações, priorizando os assentamentos da reforma agrária, as comunidades tradicionais indígenas e comunidades quilombolas [30].

A lógica dos dois programas brasileiros é vincular a produção familiar com as compras governamentais. Polman et al. (2010) [31] descrevem que o PAA criou uma conexão entre a redução da pobreza (Fome Zero e os programas de alimentação escolar) para melhorar a subsistência dos agricultores pobres, associando mercados de proximidade dentro dos processos de desenvolvimento rural. Políticas de aquisições do governo oferecem aos produtores novos mercados, fornecendo alimentos para instituições governamentais (escolas públicas, exército, hospitais, etc.) e também lhes permite começar a participar nos mercados locais, servindo novos consumidores locais [32]. A alimentação escolar é um mecanismo básico para a criação de novos mercados para agricultura familiar [33].

Na concepção do PNAE estabelece-se que os cardápios da alimentação escolar deverão utilizar gêneros alimentícios básicos, respeitando-se as referências nutricionais, os hábitos alimentares, a cultura e a tradição alimentar da localidade, pautandose na sustentabilidade e diversificação agrícola da região, na alimentação saudável e adequada [30]. Porém, Gabriel et al. (2012) [34] relatam que a aquisição dos gêneros alimentícios da agricultura familiar local se mostrou restrita em estudo realizado em duas capitais brasileiras. Alguns fatores como dificuldades nas licitações nas compras, infraestrutura de entrega e quantidade fazem com que muitos agricultores locais não consigam comercializar para esse mercado local e portanto, as prefeituras passam a comprar de agricultores de outras regiões. Da mesma maneira Belik \& Silipradi (2012) [35] destacam as dificuldades encontradas pela pequena produção para a colocação de produtos locais em regiões metropolitanas ou municípios onde simplesmente a produção local não é suficiente para abastecer a demanda governamental.

A agricultura patronal brasileira também tem buscado inserir a importância de outras questões como a sustentabilidade, incluindo questões sociais e ambientais. Dentro dessa perspectiva, o Governo Federal criou em 2010 o Plano de Agricultura de Baixa Emissão de Carbono (Plano ABC) com o objetivo de reduzir as emissões de $\mathrm{CO}_{2}$ através do financiamento de práticas e tecnologias adequadas [36]. Verifica-se no Programa $\mathrm{ABC}$ que a preocupação é semelhante ao foodmiles quanto às emissões de GEE, mas, nesse caso, o enfoque é tanto com a quilometragem rodada, mas, com a diminuição de GEE em diversas etapas da produção como o tratamento de resíduos da agropecuária, plantio de florestas, etc.

De qualquer maneira, deve-se observar que na implementação de qualquer sistema público de alimentação, como por exemplo ,a alimentação escolar em uma região, não podemos pensar em uma lógica apenas de oferta e demanda como descrito por O'Sullivan (2012) [6], mas sim como um Foodshed com implicações para a o desenvolvimento territorial. Há outras questões envolvidas como Gabriel et al. (2012) [34] descrevem das dificuldades de infraestrutura como a falta no local de Food Hubs ou mais laços entre os atores sociais (Embeddedness). Os sistemas locais podem ter um objetivo mais social de inclusão de pequenos produtores e dinamização da economia local, mas, necessita-se verificar se esses objetivos estão sendo alcançados. Ou, a produção local pode se dar pela lógica de ser contra o poder de grandes corporações, mas, não elimina a possibilidade de grandes diferenças de poder e questões políticas locais.

\section{CONSIDERAÇÕES FINAIS}

A discussão de sistemas agroalimentares locais ou produção local de alimentos introduz novos conceitos que carregam características de acordo com a finalidade para a qual foram criados. Verifica-se que nos Foodsheds há uma forte relação com o espaço e com a capacidade desse espaço ofertar alimentos aos consumidores locais. O Foodmiles é defendido principalmente dentro de uma lógica ambiental de economizar quilometragens que o alimento percorre e assim diminuir os GEE, por exemplo, o $\mathrm{CO}_{2}$. O Embeddedness é adotado principalmente com o objetivo de destacar relações sociais como os laços nas relações entre produtores e consumidores, bem como outras 
relações como as com o espaço, por exemplo, como destacado por Murdoch, Marsden e Banks (2000) [18], a apropriação de ecologias locais.

As cadeias curtas também vêm sendo trabalhadas tanto dentro da lógica ambiental de diminuir a emissão de GEE, bem como no fortalecimento dos laços sociais e da maior proximidade de informações entre produtores e consumidores.

Porém, mesmo levando-se em conta que cada conceito tem características específicas interferindo nas decisões de política pública ou nas posições dos atores sociais devemos dirigir o olhar para as diversas questões que interferem no meio rural. Uma localidade não está isolada de interferências externas, como por exemplo, a influência política o poder das grandes corporações, conflitos com outras localidades etc. Essas interferências poderão determinar a viabilidade na implantação do sistema local planejado.

Os conceitos aqui discutidos e presentes na literatura internacional ajudam a entender a dinâmica dos sistemas agroalimentares locais e a sua possibilidade de promoção como forma de organização alternativa frente aos mercados mundiais de alimentos. Mesmo que a abordagem tenha características semelhantes a sua origem, os objetivos variam de acordo com o contexto local, por exemplo, se a preocupação é mais em oferecer alimentos de qualidade aos consumidores ou promover $\mathrm{O}$ desenvolvimento rural de um determinado espaço através de novos mercados para os produtores rurais.

\section{REFERÊNCIAS}

[1] Smith A. Investigação sobre a natureza e as causas da riqueza das nações. São Paulo: Abril; 1979 (Coleção Os Pensadores).

[2] McMichael P. A food regime genealogy. J Peasant Stud. 2009;36(1):139-169.

[3] Kloppenburg J, Hendrickson J, Stevenson GW. Coming into the Foodshed. Agric Human Values. 1996;13(3):33-42.

[4] Peters CJ, Bills NL, Lembo AJ, Wilkins JL, Fick GW. Mapping potential foodsheds in New York State: a spatial model for evaluating the capacity to localize food production. Renewable Agriculture and Food Systems. 2009;24(1):72-84.
[5] Feenstra GW. Local food systems and sustainable communities. Am J Alternative Agr. 1997:12(1):28-36.

[6] O'Sullivan K. Locavoracious: What are the impacts and feasibility of satisfying food demand with local production? [internet]. Geoverse, 2012 [acesso em 06 marc 2013]. Disponível em: http://geoverse.brookes.ac.uk/article_resources/osullivanK .htm.

[7] Feagan R. The place of food: mapping out the "local" in local food systems. Prog Hum Geog. 2007;31(1):23-42.

[8] Foodshed. Field Guide to the New American Foodshed [acesso em 10 marc 2013]. Disponível em: http://foodshedguide.org/foodshed.

[9] Morley A, Morgan S, Morgan K. Food Hubs: The "Missing Middle" of the Local Food Infrastructure. Research Report for the Welsh Assembly Government. Brass: Cardiff University; 2008.

[10] Du Puis EM, Goodman D. Should we go "home" to eat?: toward a reflexive politics of localism. J Rural Stud. 2005;21(3):359-371.

[11] Kemp K, Insch A, Holdsworth DK, Knight JG. Food miles: Do UK consumers actually care? Food Policy. 2010;35(6):504-513.

[12] Iles A. Learning in Sustainable Agriculture: Food Miles and Missing Objects. Environmental Values. 2005,14(2):163-183.

[13] União Europeia. Parecer do Comité das Regiões sobre "Sistemas alimentares locais". 88 8 a Sessão plenária de 27 e 28 de janeiro de 2011. Jornal Oficial da União Europeia. 2.4.2011, C 104/1-6. [acesso em 11 marc 2013]. Disponível em: $\quad$ http://eurlex.europa.eu/LexUriServ/LexUriServ.do?uri=OJ:C:2011:1 04:0001:0006:PT:PDF.

[14] Coley D, Howard M, Winter M. Local food, food miles and carbon emissions: A comparison of farm shop and mass distribution approaches. Food Policy. 2009;34(2):150155.

[15] USDA - United States Department of Agriculture. Local Food Systems: Concepts, Impacts, and Issues. Martinez S. et al. Economic Research Service, Economic Research Report 97; 2010.

[16] Sonnino R, Marsden TK. Beyond the divide: rethinking relationships between alternative and conventional food networks in Europe. J Econ Geogr. 2006;6(2):181-199. 
[17] Hinrichs CC. Embeddedness and local food systems: notes on two types of direct agricultural market. J Rural Stud. 2000;16(3):295-303.

[18] Murdoch J, Marsden TK, Banks J. Quality, Nature, and Embeddedness: Some Theoretical Considerations in the Context of the Food Sector. Econ Geogr. 2000;76(2):107125.

[19] Van der Ploeg JD, Renting H, Brunori G, Knickel K, Mannion J, Marsden T, Roest K, Sevilla-Guzmán E, Ventura F. Rural Development: From Practices and Policies towards Theory. Sociologia Ruralis. 2000;40(4):391-408.

[20] Renting H, Marsden TK, Banks J. Understanding alternative food networks: exploring the role of short food supply chains in rural development. Environ Plan A. 2003;35(3):393-411.

[21] Miele M, Murdoch J. The Practical Aesthetics of Traditional Cuisines: Slow Food in Tuscany. Sociologia Ruralis. 2002;42(4):312-328.

[22] Hinrichs CC, Kremer KS. Social Inclusion in a Midwest Local Food System Project. J Poverty. 2002;6(1):65-90.

[23] Morgan K, Sonnino R. The School Food Revolution: Public Food and the Challenge of Sustainable Development. London: Earthscan, 2008.

[24] Izumi BT, Wright DW, Hamm MW. Market diversification and social benefits: Motivations of farmers participating in farm to school programs. J Rural Stud. 2010;26(4):374-382.

[25] Feenstra G, Ohmart J. The Evolution of the School Food and Farm to School Movement in the United States: Connecting Childhood Health, Farms, and Communities. Childhood Obesity. 2012;8(4):280-289.

[26] Sonnino R. Quality food, public procurement, and sustainable development: the school meal revolution in Rome. Environ Plan A. 2009;41(2):425-440.

[27] Sonnino R, Mcwilliam S. Food waste, catering practices and public procurement: A case study of hospital food systems in Wales. Food Policy. 2011;36(6):823-829.

[28] Graziano da Silva JF, Belik W, Takagi M. Os Desafios de uma política de Segurança Alimentar no Brasil. In: Cimadamore A, Hartley D, Siqueira J. (org.). A pobreza do Estado: reconsiderando o papel do Estado na luta contra a pobreza global. Buenos Aires: CLACSO, 2006, p. 151-170.
[29] Brasil. Lei no. 10.696 de 2 de julho. Diário Oficial da União (D.O.U.) 03 jul. 2003 [acesso em 10 marc 2013]. Disponível em: http://www.planalto.gov.br/CCIVIL/Leis/2003/L10.696. htm.

[30] Brasil. Lei no. 11.947 de 16 de junho. Diário Oficial da União (D.O.U.) de 17 jun. 2009 [acesso em 10 marc 2013]. Disponível http://www.planalto.gov.br/ccivil_03/Ato20072010/2009/Lei/L11947.htm.

[31] Polman N, Poppe KJ, Van der Schans J, Van der Ploeg JD. Nested Markets with Common Pool Resources in Multifunctional Agriculture. Rivista Di Economia Agraria. 2010;65(2):295-318.

[32] Schneider S, Shiki S, Belik W. Rural development in Brazil: overcoming inequalities and building new markets. Rivista Di Economia Agraria. 2010; 65(2):225-259.

[33] Van der Ploeg JD, Jingzhong Y, Schneider S. Rural development reconsidered: building on comparative perspectives from China, Brazil and the European Union. Rivista Di Economia Agraria. 2010;65(2):163-190.

[34] Gabriel CG, Costa LCF, Calvo MCM, Vasconcelos FAG. Planejamento de cardápios para escolas públicas municipais: reflexão e ilustração desse processo em duas capitais brasileiras. Rev Nutr. 2012;25(3):363-372.

[35] Belik W, Siliprandi E. A Agricultura Familiar e o Atendimento à Demanda Institucional das Grandes Cidades In: Corá MAJ, Belik W. Projeto Nutre SP: análise da inclusão da agricultura familiar na alimentação escolar no estado de São Paulo. São Paulo: Instituto Via Pública; 2012. p. 61-66.

[36] MAPA - Ministério da Agricultura, Pecuária e Abastecimento. Plano ABC [acesso em 28 marc 2013]. Disponível em: http://www.agricultura.gov.br/desenvolvimentosustentavel/plano-abc. 